\title{
Pedagogy vs. Market Needs: An Appraisal of a Graduate Program in Translation and Interpreting
}

\author{
Aïda Seddik
}

Higher Institute of Human Sciences of Tunis, Tunisia University of Tunis El Manar

ARTICLE INFO

Keywords:

Higher education

Internal and external

Assessments

Mixed methods

Program evaluation

Translation and

interpreting studies

\begin{abstract}
The paper is an evaluation of the professional MA program in Translation and Interpreting in a higher education institution in Tunisia. Two research questions were explored in order to investigate whether the program prepares students for the market needs and to present a complete picture revealing insights from multiple sources. Data were collected in two phases through the use of six instruments including a questionnaire for MA students, a questionnaire for former students, a questionnaire for teachers, a structured interview with the MA coordinator, structured interviews with employers and a qualitative content analysis of the course distributions of the MA program. Data analysis revealed that the program responds to the market needs in translation but not in interpreting. All stakeholders strongly agreed on the need for more practice in interpreting. Based on these findings, some recommendations were put forward. These include mainly the need to reconsider the pedagogy by increasing the amount of learning time, involving additional subjects such as soft, life and marketing skills, and providing professional practices, namely internship opportunities.
\end{abstract}

\section{Introduction}

This study evaluates the professional MA program in Translation and Interpreting at Institut Supérieur des Sciences Humaines de Tunis (ISSHT, Higher Institute of Human Sciences of Tunis). It is one of three similar MA programs available Tunisia. It is coordinated by the department of Translation and offers a professional MA degree which can be completed in four semesters; three for courses and one for the thesis writing.

The MA program in translation and interpreting ISSHT

$$
\begin{aligned}
& \text { One of the } 3 \text { MA } \\
& \text { programs in Tunisia } \\
& (2009-2010)
\end{aligned}
$$

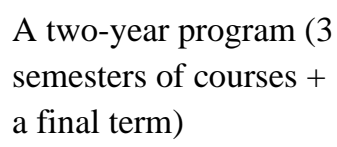

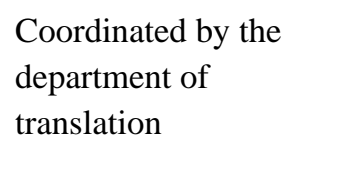

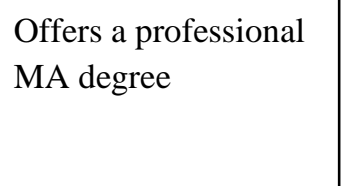

Figure 1. Context of the study

The present study investigates whether the MA program prepares students for the market needs. This evaluation used a mixed-method approach in order to collect data from internal and external assessments. The internal assessments involved insights from MA students (both first and second-year), teachers (both academics and professionals), the coordinator of the MA studies, and curriculum documents in general and course distributions in particular. Insights

* Corresponding Author E-Mail Address: seddikaida75@yahoo.com 
from external assessments included former students and employers. Data collected from all sources were analyzed and corroborated so as to present a clear and complete picture of the MA program.

\subsection{Need for the study}

Conducting program evaluation in higher education institutions is highly recommended for successful education (Golden et al., 2015; Rezvani \& Vakilinejad, 2014). Though the literature highlights the need for conducting evaluation, research in this area has not received much attention abroad (Rezvani \& Vakilinejad, 2014) as well as in Tunisia (Seddik, 2017; Seddik \& Selmi, 2015).

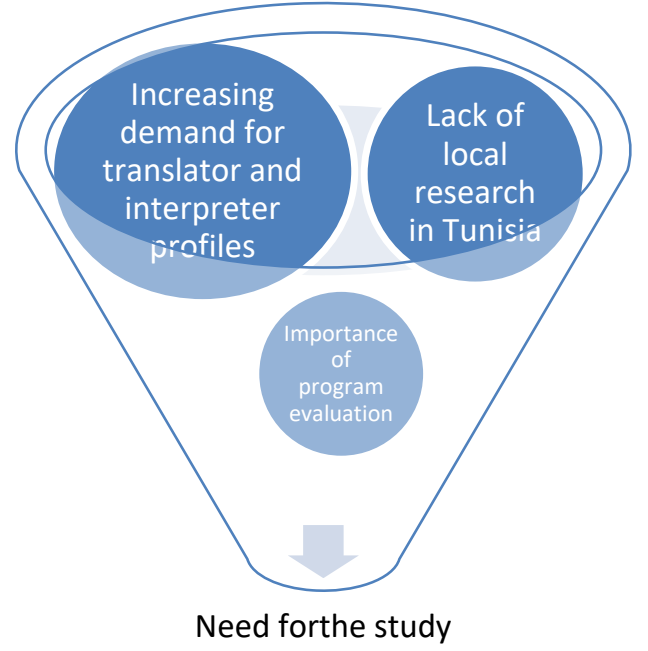

Figure 2. Need for the study

\subsection{Purpose}

The main aim of this study is to investigate whether the MA program responds to the market needs. The specific objectives are as follows:

- To determine the insights of various stakeholders including MA students, former students, teachers, the coordinator as well as employers

- To examine the structure of course distributions of the MA program by conducting a qualitative content analysis

The study seeks to respond to the following research questions:

- Does the MA program respond to the market needs?

- What are the viewpoints of various stakeholders?

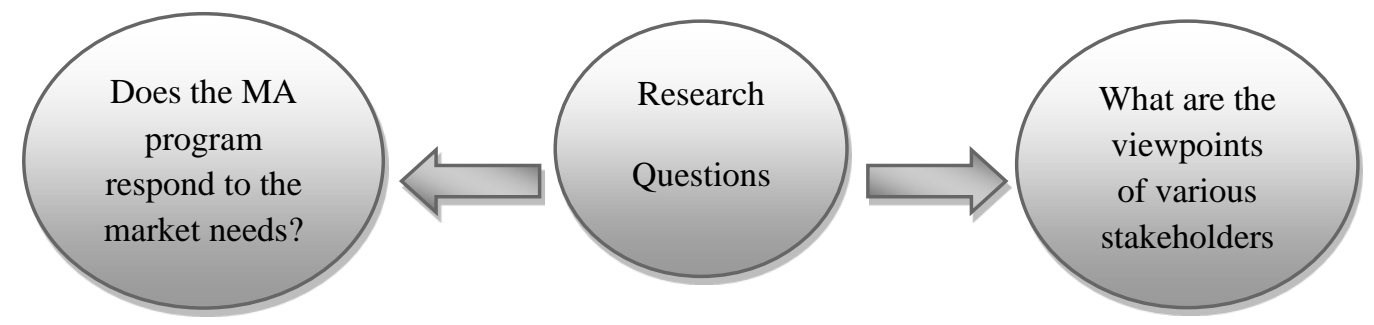

Figure3. Research questions

\section{Methods}

Data were collected in two phases through a combination of quantitative and qualitative instruments designed for different stakeholders in connection with the professional MA program in Translation and Interpreting (See Table 1). The mixed-method approach included collecting data through a variety of instruments in the first stage. These consisted of a 
questionnaire for MA students (both first and second-year students), a questionnaire for MA teachers, another questionnaire for former MA students, and a structured interview with the coordinator of the MA program, and structured interviews with employers. The second stage focused on a qualitative content analysis. Given the importance of piloting, all instruments were first tested with a colleague teaching in the MA program. The researcher asked her colleague to read and give feedback on the questions enclosed. Then the questionnaires were piloted on a limited number of respondents from each target population who provided useful comments and indicated areas which required revision. Piloting these instruments helped the researcher estimate the time needed for their completion. While the administration of the questionnaires took place in April and May 2019, the interviews were conducted in August 2019. Data collected gleaned answers to the research questions investigating whether the MA program answered the market needs as perceived by stakeholders. A detailed description of each instrument used in this study is presented below. The order in which instruments are presented corresponds to the order in which they were administered.

Table 1.

Data collection instruments

\begin{tabular}{|c|c|c|c|c|}
\hline Phase & Data collection instruments & $\begin{array}{l}\text { Data analysis } \\
\text { procedures }\end{array}$ & Sample & $\begin{array}{l}\text { Number } \\
(\mathrm{N})\end{array}$ \\
\hline \multirow[t]{5}{*}{1} & a.Questionnaire for MA students & Quantitative & $1 \mathrm{st}+2^{\text {nd }}$ year students & $24+12=36$ \\
\hline & b. Questionnaire for former students & Qualitative & Former students & 5 \\
\hline & c. Questionnaire for teachers & Quantitative & MA teachers & 11 \\
\hline & d. Structured interview with Coordinator & Qualitative & $\begin{array}{l}\text { Coordinator of the MA } \\
\text { program }\end{array}$ & 1 \\
\hline & e. Structured interviews with Employers & Qualitative & $\begin{array}{l}\text { Chief interpreter } \\
\text { General director }\end{array}$ & 2 \\
\hline 2 & Content Analysis & Qualitative & $\begin{array}{l}\text { Course distributions (SI, } \\
\text { SII \& SIII) }\end{array}$ & 3 \\
\hline
\end{tabular}

\subsection{Phase 1}

\subsubsection{Questionnaire for MA students}

The first instrument was the questionnaire intended for both first and second-year MA students. It was administered to 24 first-year and 12 second-year students. As can be seen from Table 2, a total of 36 students completed anonymously and returned the questionnaire. Students as well as their teachers were cooperative as they helped the researcher to administer and then collect the questionnaire in their classes. The coordinator's cooperation was also extremely helpful in collecting data especially from a considerable number of second-year students who had no longer classes in Semester 4 and to whom the researcher could have no access.

Table 2.

Data collected from MA students

\begin{tabular}{lcc}
\hline Level & Total number of students enrolled & Number of respondents \\
\hline $1^{\text {st }}$ year students & 40 & 24 \\
$2^{\text {nd }}$ year students & 43 & 12 \\
$1^{\text {st }}+2^{\text {nd }}$ year students & 83 & 36 \\
\hline
\end{tabular}

\section{Description}

The introductory part of the questionnaire collected biographical information including gender, level of education and age. These opening items were followed by a list of 5 closed questions. Table 3 provides a brief description of the items introduced in the first instrument. 
Table 3.

Summary of MA students' questionnaire items

\begin{tabular}{ll}
\hline Item & Theme \\
\hline Q1 & Adequateness of learning hours per subject \\
Q2 & Need for more practice in Translation and Interpreting \\
Q3 & Usefulness of courses taught for working career: Areas for improvement \\
Q4 & Awareness of the Translation and Interpreting market needs \\
Q5 & Further suggestions related to the courses \\
\hline
\end{tabular}

\subsubsection{Questionnaire for Former Students}

The second instrument used to collect data in order to answer whether the MA program responded to the market needs was the questionnaire designed for former MA students. Former students represented an important source in revealing whether the MA program prepared them for the professional career (Ramaswami et al., 2012; Seddik, 2017). Indeed, Dubin and Olshtain (1986) viewed graduates "who may have taken on various jobs in the community" (p.3) a crucial source in revealing the concrete needs in the real work environment.

\section{Sample}

The sample consisted of 5 former students who have recently graduated. Access was not easy since these graduates had left the university. Though small, this sample was representative of the target population as all the respondents were working in the fields of translation and interpreting.

\section{Description}

Two opening items enquiring about gender and year of graduation were included in this instrument followed by a total of 8 questions. Table 4 displays a succinct description of the themes covered within this instrument.

Table 4.

Summary of MA former students' questionnaire items

\begin{tabular}{ll}
\hline Item & Theme \\
\hline Q1 & Currently working or not \\
Q2 & Securing a job immediately after graduation \\
Q3 & Adequateness of number of learning hours they had \\
Q4 & Preparedness of the training they have had for their working career: \\
& Weaknesses/Areas for improvement \\
Q5 & Use of translation and interpreting skills they have learnt within the program \\
Q6 & Effect of studies on the mastery of active and passive languages \\
Q7 & Difficulties in the field faced when you started working \\
Q8 & Further additions or suggestions \\
\hline
\end{tabular}

\subsubsection{Questionnaire for MA teachers}

The third instrument used for collecting data in this study was the Questionnaire for MA teachers. Teachers are usually reported to be an important source for determining whether any educational program responds to the market needs (Seddik, 2017; Seddik \& Selmi, 2018).

\section{Sample}

Fourteen (14) teachers (both academics and professionals) were involved in the MA team in the academic year 2018-2019. The administration of this questionnaire was intended to include all these teachers. Yet, this was not the case and the administration involved 11 teachers as the remaining were professionals and were out of reach since data were collected by the end of the 
same academic year and professionals seemed to be very busy and did not answer phone calls when the researcher tried to contact them.

\section{Description}

The questionnaire covered 6 opening items enquiring about the bio-data of the respondent. These items generated information about gender, job position, years of experience within this MA program, years of teaching in general, years of teaching experience in translation studies, and years of professional experience. Table 5 provides a brief summary of the items displayed in this instrument.

Table 5.

Summary of MA teachers' questionnaire items

\begin{tabular}{ll}
\hline Item & Theme \\
\hline Q1 & Level (s) you are teaching this year \\
Q2 & Course (s) you are teaching per level \\
Q3 & Setting clear aims and objectives \\
Q4 & Preparing course description (s) for course (s) \\
Q5 & Adequateness of teaching time for subject (s) you teach \\
Q6 & Usefulness of course (s) for your graduates' working career \\
Q7 & Awareness of the market needs \\
Q8 & Evaluation of the level of students in translation and interpreting \\
Q9 & Further suggestions \\
\hline
\end{tabular}

\subsubsection{Structured Interview with the MA Coordinator}

A structured interview was conducted with the coordinator of the MA program. The interview sought to collect some general information about the MA program such as its establishment, aims and usefulness. This information could not have been provided by any other source. The interview included 18 questions and was conducted in August 2019 and lasted 30 minutes. Table 6 presents a synopsis of the themes covered within this instrument.

Table 6.

Summary of the items included in the structured interview with coordinator

\begin{tabular}{ll}
\hline Item & Theme \\
\hline Q1 & Date of the establishment of the program \\
Q2 & Any update since its establishment \\
Q3 & Demand for the MA studies: Increasing? \\
Q4 & Number of MA students: Increasing? \\
Q5 & Existence of clear aims and objectives for MA program \\
Q6 & Existence of a clear official document \\
Q7 & Availability of concrete course descriptions \\
Q8 & Appropriateness of courses to the objectives of the program \\
Q9 & Availability of opportunities to translate and interpret in real-world settings \\
Q10 & Program offering support \\
Q11 & Courses specialized are enough for target students \\
Q12 & Amount of learning time: sufficient to provide adequate training? \\
Q13 & Team involved in teaching: Academics/ Professionals \\
Q14 & Problems finding right teachers \\
Q15 & Difficulties faced by graduates to get into the market after graduation \\
Q16 & Awareness of the market needs \\
Q17 & Adequateness of the demands of the market with the training offered in the program \\
Q18 & Further comments/ suggestions/ recommendations \\
\hline
\end{tabular}




\subsubsection{Structured Interviews with Employers}

The fifth and final instrument used for collecting data within Phase 1 was the structured interview with employers. "Formal feedback from (...) employers will improve areas that need refining the curriculum (...).” (Pool \& Sewell, 2007, p. 284).

\section{Sample}

These interviews were conducted with 2 out of 7 employers contacted. Only 2 employers were willing to respond to the interview questions. These were conducted in August 2019 and lasted approximately 20 minutes each.

\section{Description}

This instrument was adapted from an instrument used in a paper that the researcher copresented in an international conference (Seddik \& Selmi, 2018). The interview guide consisted of 6 opening items and 7 closed and open-ended questions. The first part of the questionnaire collected bio-data revealing information about gender, place of work, type of company, job position, work experience within the company and the overall work experience. Table 7 displays a brief description of the items included in the second part of the interview guide.

Table 7.

Summary of the items included in the structured interviews with employers

\begin{tabular}{ll}
\hline Item & Theme \\
\hline Q1 & Type of profile needed in your company \\
Q2 & Need for translator and interpreter profiles in your company \\
Q3 & Need for such profiles: Increasing or not \\
Q4 & Trouble hiring translators and interpreters \\
Q5 & Place of graduation of your employees \\
Q6 & Evaluation of their work level in general and in translation and interpreting fields \\
Q7 & Further comments/ recommendations to better meet job requirements in the future \\
\hline
\end{tabular}

\subsection{Phase 2: Content Analysis}

This qualitative instrument involved a thorough description (see Table 8) and a careful analysis of the course distributions of the three semesters spread over both levels (the $1^{\text {st }}$ and the $2^{\text {nd }}$ ) of the program. These were the only documents that the researcher could obtain.

Table 8.

Course distributions of the 3semesters (English: E-Arabic: A)

\begin{tabular}{lll}
\hline \multicolumn{1}{c}{ SI (N=11) } & \multicolumn{1}{c}{ SII (N=10) } & \multicolumn{1}{c}{ SIII (N=10) } \\
\hline General translation (E-A) & General translation (E-A) & Translation in the Arabic culture (A) \\
General translation (A-E) & General translation (F-A) & Translation studies (E) \\
Translation methodologies (F-A) & General translation (A-E) & Translating sciences (E-A) \\
Cultural translation (A \& E) & Literary translation (A) & Business translation (F-A) \\
International relations (F) & Commercial translation (F-E) & Legal translation \\
Grammar (A) & Business translation (E-A) & Legal translation (A-E) \\
Language \& terminology (A) & Audio-visual translation (A-E) & Consecutive interpreting (E/F-A) \\
Intercultural studies (A) & Interpreters and conferences (E) & Simultaneous interpreting (A/F-E) \\
Introduction to interpreting (E) & Simultaneous interpreting (E-A) & Drafting documents (Arabic) \\
Linguistics (E) & Discourse analysis (A) & Research methodologies (E) \\
Law (A) & & \\
\hline
\end{tabular}

In translation and interpreting studies, it is generally recommended to include several components namely language courses (Olvera Lobo et al., 2005), cultural and world knowledge courses (Tosun et al., 2015), a general translation training (Freihoff, 1993 cited in Tosun et al., 2015), interpreting, computer technology in general (Olvera Lobo et al., 2005) and computer- 
assisted translation in particular (Gouadec, 2000; Kautz, 2000 cited in Tosun et al., 2015), and more importantly knowledge and skills from a variety of disciplines, also known as courses on specialized fields (Amman \& Vermeer, 1990 cited in Tosun et al., 2015; Freihoff, 1993 cited in Tosun et al., 2015; Olvera Lobo et al., 2005; Tosun et al., 2015). These specialized courses are viewed to be significant given that translation draws on various disciplines (Olvera-Lobo et al., 2005).

Based on the literature in this field, these specialized courses may include Documentation, Terminology, Desktop Publishing (Olvera-Lobo et al., 2005), technical fields, law, economics and medicine (Amman \& Vermeer, 1990 cited in Tosun et al., 2015), economics, business administration, law, literature, European Union, international relations and politics (Tosun et al., 2015). In fact, availability of these courses represents " $t$ t]he most important indication of the development of translation departments" (Tosun et al., 2015, p. 7). So, an adequate structure of the course distributions in this study would include each of the elements described earlier. These components were grouped for the sake of clarity in Table 9 representing a framework for evaluating the course distributions of the 3 semesters of the MA program.

Table 9.

Framework for evaluating the course distributions

\begin{tabular}{|l|l|l|}
\hline & Elements included & Elements omitted \\
\hline Language courses & & \\
\hline Cultural and world knowledge courses & & \\
\hline Translation & & \\
\hline Interpreting & & \\
\hline Specialized courses & & \\
\hline Computer technology & & \\
\hline Other & & \\
\hline
\end{tabular}

\section{Results and Discussion}

The present section describes the results obtained from the various instruments displayed in the previous section. Each subsection displays results collected from each instrument as perceived by each stakeholder involved in this study. Then the main findings are presented in relation to the research questions stated earlier (see section 1.2).

\subsection{Response to the market needs a. Insights from MA students}

This subsection presents data generated from the questionnaire administered to MA students. Data were collected from 36 respondents. Twenty-four were enrolled in the first and 12 in the second year. Data from each level were first reported separately. Then data from both levels $(\mathrm{N}=36)$ were combined to elicit more revealing results producing accurate viewpoints and a clear picture of the MA program in Translation and Interpreting.

Feedback from students revealed that the MA program in translation and interpreting responded to the market needs as nearly all students were aware of the translation and interpreting market needs and perceived the MA courses as useful for their working career. In spite of their awareness and agreement, half of the students claimed that the number of learning hours was not adequate and stressed the need for more hours in general and for interpreting courses in particular. They also highlighted the need for more practice in their areas of specialization. Indeed, they maintained that more practical activities, specialized courses and additional language courses, namely Grammar and Phonetics in English are required. 


\section{b. Insights from former MA students}

This subsection reports on the qualitative data collected from 5 former students. Based on the questionnaire for former students, data showed that most respondents found that the number of learning hours was not enough though one admitted that "each hour was a gift. I learned a lot at university". Respondents who were dissatisfied explained that this was true especially for interpreting as they had only one single course ( 2 hours per week).

Based on this instrument, results showed that the respondents were satisfied with the MA program as far as the translation skills were concerned. They all agreed that the studies prepared them for the translation market needs and admitted that they were still using the skills they learned. They also acknowledged that they had a good mastery of active and passive languages. Yet, they expressed their dissatisfaction with the number of learning hours they had and claimed as a result the need for more practice. They confessed that the courses in interpreting did not prepare them for work and pointed out some weaknesses that were related to the MA program. These included the absence of the French language, the need for more hours for interpreting, the need for field visits and the shortage of teachers specialized in these fields. It is good to remind the reader that these former students were in the old regime and the MA degree they had was entitled an MA degree in translation yet not translation and interpreting. Among the difficulties they faced at work, former students listed lack of experience, lack of interpreting skills (mainly consecutive skills) and the failure to be introduced in the professional market.

Compared to students' viewpoints, former MA students were exactly similar. Both respondents' answers were split related to whether the number of learning hours was adequate or not and claimed the need for more practice in general and for more interpreting courses in particular. Both claimed the need to include French in the syllabus though this MA program focuses on the language combination Arabic and English as stated by the coordinator. Additionally, both valued the importance of practical experience in these fields. Indeed, including professional practice has also been stressed in the literature. For instance, de Céspedes (2017) highlighted the usefulness of these practices in the Translation curriculum. According to him, the incorporation of these initiatives "provides and facilitates a well-rounded set of employability skills that can be applied to the whole programme of study, or a specific unit" (p. 117).

\section{c. Insights from MA teachers}

Data were collected from 11 out of the 14 teachers who make up the MA team. All respondents had a considerable teaching experience in general as well as in translation studies and in the MA program in particular. Concerning professional experience, 4 respondents had a professional experience that ranged from 15 to 24 years. Most teachers $(\mathrm{N}=8)$ taught both levels. All respondents provided the course(s) they taught per level. The number of the courses elicited in this question reached 26 out of 31 courses; 17 were delivered at the first level and 9 at the second level. These titles matched the titles of the courses listed in the three course distributions that were described in Table 8.

Data collected from the questionnaire for MA teachers disclosed that nearly all the courses they taught were useful for the graduates' working career and had clear aims. Yet, not all of them had course descriptions. Concerning the teaching time, the respondents' answers were split and nearly all professionals were dissatisfied and claimed the need for more hours for practice. This finding was in line with findings generated from both students and former students. The three stakeholders highlighted the need for more practice for their studies. As for the evaluation of the students' level in translation and interpreting, only professionals provided answers. They reported that the level of their students varied as there were excellent, good, average and poor students. A few were even in the wrong degree according to some teachers. 


\section{d. Insights from the MA coordinator}

The MA program in Translation and Interpreting is one of two similar MA programs in Tunis. This program was established in 2009-2010 and has been updated in 2018. It used to hold the title MA in Translation and became MA in Translation and Interpreting. Amendments were introduced so as to include the interpreting component in the program, which is highly required by the job market. This is the first time in Tunisia that an MA program specializes in both translation and interpreting.

The major findings yielded from the structured interview with the coordinator disclosed that the demand for the MA program (specific to the language combination English \& Arabic) was quite enormously increasing. This program had clear aims and objectives stated in a clear official document though the researcher could not have access to this document. The interviewee stated the main aims include introducing students to the job market and upgrading their translational, interpreting and interpretational skills. He also acknowledged that only some teachers provided course descriptions yet admitted that all courses were appropriate to goals of the program. Furthermore, he perceived that there were enough specialized courses which are likely to meet the market needs. All courses were adequate with these needs. He reported that he was aware of the needs since he was involved in the market. The coordinator stated that students had opportunities to translate and interpret in real world settings during studies. Courses within the program were delivered by both academics and professionals. Involving professionals is of paramount importance in such a professional program.

The only problem revealed by the interviewee was the short time allocated to training. According to him, three semesters were not enough to produce very qualified translators and interpreters. This finding does not correspond to data yielded from an earlier item enquiring whether the amount of learning time was sufficient. It becomes clear that there is a mismatch in the interviewee's answers. This was similar to the mismatch identified in all other stakeholders' responses. The same split was reported in students', former students' and teachers' viewpoints. Learning time seems to be a real and common problem for nearly all stakeholders involved in this study. Something needs to be done concerning the amount of time. Overall, the professional MA program responded to the market needs and the training period seemed the only element that needed reconsideration.

\section{e. Insights from employers}

Two structured interviews were held with two respondents working in different event organization companies. One was a chief interpreter and the second was a general director. They both had a long overall work experience and a considerable experience within their companies.

Both interviewees agreed that the need for translator and interpreter profiles was enormously increasing and that the market was in need especially for novice interpreters. Indeed, some companies were looking for cheaper interpreting services. Both respondents stated that there were times when you could not find a single translator or interpreter. Both interviewees were satisfied with the graduates' qualifications. Additionally, they specified that these were highly qualified and had great language and interpreting skills though they were not specialized in this field and had their degree from various departments of English in higher education institutions. One of the two interviewees reported that he recruited MA students for translation tasks and acknowledged that they were well-trained in spite of some weaknesses.

What can be concluded is that the MA program in Translation and Interpreting responds to the market needs as far as translation was concerned. Yet, this was not the case for interpreting as he reported that these graduates had weaknesses in speaking, soft and marketing skills. Experience was crucial in recruiting employees for interpreting tasks. In order to overcome these problems, both interviewees suggested the need to offer MA students courses on soft, life 
and manner skills in addition to opportunities for internship. The inclusion of these courses is likely to improve the interpreter profile and hence respond to the market needs.

\subsection{Content analysis}

In order to investigate whether the course distributions of the MA program prepared students for the market needs, a careful analysis of the 3 course distributions was conducted. In a first position, each course distribution was presented separately then data from all documents were combined so as to provide a clear image of the whole structure of the MA program.

Based on the course distribution of the first semester (SI), data showed that courses were varied. They included a single language course (Arabic Grammar), one cultural course (Intercultural Studies A), 4 courses in Translation (General Translation A -E, General Translation A -E, Cultural Translation A \& E and Translation Methodologies A), one course in Interpreting (Introduction to Interpreting), and 4 specialized courses (Language Terminology A, Law A, Linguistics E and International Relations F). A notable omission concerned computer technology courses. What can be noted from this distribution was that the course distributions met the requirements needed for an appropriate structure in translation and interpreting. Courses within each component were available except for courses in computer technology. It is also clear that the focus was more evident on translation than on interpreting courses. This finding was in line with findings from other instruments confirming students' and teachers' viewpoints.

Focusing on the course distribution of the $2^{\text {nd }}$ semester, data highlighted the emphasis put on courses in Translation. Indeed, there were 7 courses included within this component. Again, it seems clear that the focus was more on translation courses as there were only two courses in interpreting. In addition to courses within translation and interpreting, there was a unique specialized course delivered in Arabic. This was Linguistics (Discourse Analysis). Not a single course was delivered within one of the following modules (Language, Cultural and World Knowledge \& Computer Technology) though these courses are considered to be important in the structure of these studies.

As regards course distributions in the third semester (SIII), data indicated a variety of courses. As for the two previous distributions (SI, SII), 4 courses were devoted to Translation (Legal Translation A -E, Translating Sciences E-A, Business Translation F-A (elective), Legal Translation F-A (elective)), 2 courses to Interpreting (Consecutive Interpreting E/F-A, Simultaneous Interpreting A/F-E), 1 Cultural and World Knowledge course, 1 language course (Administrative Writing: Drafting Documents in Arabic) and a course in Research Methodology given that students have to submit a dissertation by the end of term IV. Unlike the previous course distributions (SI \& SII), a notable omission was noted related to specialized courses. Not a single course was delivered at this level. Furthermore, absence of courses in Computer Technology was persistent within this distribution.

On the whole, data yielded from the 3 course distributions indicated a strong emphasis on courses in translation. Indeed, there were 15 (out of 31) courses in both general and specialized translation spread throughout the three semesters. Nearly half of the courses were devoted to translation. As opposed to translation, only 5 courses in interpreting were involved. Based on data from all course distributions, it becomes clear that there is no balance between courses in translation and courses in interpreting though the MA degree is entitled MA in Translation and Interpreting. This finding strongly matches feedback obtained from both students and former students who were in agreement. Though considered as very important in the structure of the translation studies, only 5 specialized courses were included. The availability of these courses was obvious especially in the course distributions of the first semester (SI) $(\mathrm{N}=4)$. It can also be noted that there were 2 language courses delivered in Arabic in addition to the cultural and world knowledge course. Computer technology was a notable omission from the three course 
distributions. This seems strange knowing about the importance that electronic and computer tools can bring in professional work (Gouadec, 2000).

To sum up the whole section, Table 10 presents the major findings obtained from all instruments used in both phases.

Table 10.

Summary of major findings

\begin{tabular}{|c|c|}
\hline Sample/Informant & Main results \\
\hline MA surdent & $\begin{array}{l}\text { - Number of learning hours: } 1 / 2 \text { of the respondents not adequate }(\mathrm{N}=18) \\
\text { - Courses useful for working career } \\
\text { - Need for more practice in general } \\
\text { - Need for more courses in interpreting (esp. simultaneous) } \\
\text { - Well-prepared in translation yet not in interpreting } \\
\text { > Program responds to translation but not to interpreting needs }\end{array}$ \\
\hline Former students & $\begin{array}{l}\text { - Number of learning hours: } 1 / 2 \text { of the respondents not adequate } \\
\text { (general agreement) } \\
\text { - Graduates using the translation skills they learned } \\
\text { - A good mastery of both active + passive language } \\
\text { Areas for improvement: Need more practice, inclusion of field visits, inviting } \\
\text { professionals, introduction to the field, more specialized teachers }>>\text { Importance } \\
\text { of practical experience } \\
\text { > Program responds to translation but not to interpreting market needs. }\end{array}$ \\
\hline MA teachers & $\begin{array}{l}\text { - Teaching time: } 1 / 2 \text { of the respondents not adequate (All professionals) } \\
\text { - Need more practice in Interpreting (especially simultaneous) } \\
\text { - Students' level varied according to professionals (excellent, good, } \\
\text { average and even in wrong degree) }\end{array}$ \\
\hline MA Coordinator & $\begin{array}{l}\text { > Program responds to translation but not to interpreting market needs. } \\
\text { - MA program: Clear aims and objectives } \\
\text { - } \text { All courses appropriate to objectives of studies } \\
\text { - Sraining adequate with market needs } \\
\text { - Amocialized courses: enough } \\
\text { - Opportunities to translate and interpret in real world settings during } \\
\text { - } \text { studies } \\
\text { - Cest students introduced in the work field } \\
\text { - } \text { Same time } \\
\text { Tet, program a mere introduction (not possible to produce very qualified } \\
\text { translators \& interpreters }\end{array}$ \\
\hline Employer & $\begin{array}{l}\text { - Need for translator and interpreter profiles increasing } \\
\text { - } \quad \text { Eme job market in need for novice interpreters } \\
\text { interpreting } \\
\text { - Need to offer courses in speaking, soft \& marketing skills and } \\
\text { opportunities for internship } \\
\text { - Experience must be a fundamental requirement within translation and } \\
\text { interpreting studies }\end{array}$ \\
\hline $\begin{array}{l}\text { Course distributions (SI, } \\
\text { SII \& SIII) }\end{array}$ & $\begin{array}{l}\text { > Program responds to translation but not to interpreting market needs. } \\
\text { - A strong emphasis on translation courses }(15 / 31) \\
\text { - Only } 5 \text { courses in interpreting } \\
\text { - A considerable number of specialized courses in translation } \\
\text { - Absence of courses in computer technology } \\
\text { >>Program responds to translation but not to interpreting market needs. }\end{array}$ \\
\hline
\end{tabular}




\section{Conclusion}

The main findings revealed that the MA program in focus responds to the translation market needs as students were reported to be well-trained in translation. Yet, the program does not fully meet the interpreting needs. Nearly all stakeholders' viewpoints (students', former students', teachers' and employers') were in agreement. According to them, there was no balance between courses in translation and interpreting. Though these stakeholders acknowledged that MA students were good at translation, this was not the case for interpreting. Additionally, the analysis of course distributions confirmed this finding as there was a strong emphasis on translation courses in the three course distributions of the program. While 15 courses were devoted to the teaching of translation, only 5 were assigned to interpreting and they are spread over three semesters.

\subsection{Implications}

Findings from other research confirm the need to involve several stakeholders using a variety of tools (Seddik, 2017; Spiel et al, 2006). Indeed, this evaluation endeavour is characterized by this central feature though it is acknowledged in the literature that "rarely will a single performance measurement system or evaluation study meet the information needs of all key stakeholders" (Wholey, 2001, p.345).

Another significant contribution is that the feedback generated from multiple sources can be valuable for all key stakeholders. Indeed, these viewpoints can help the coordinator and teachers design a better syllabus including appropriate courses. Research indicates that "it is pleasing that translation departments update their course schedules every year (...)" (Tosun et al., 2015, p.7). As a result, courses updated based on formal feedback can yield well-prepared graduates in the translation and interpreting fields. Graduates from this program will be equipped with the skills that will help their integration in the job market. Actually, this finding substantiates results in similar studies. Research in these fields indicates that work experience is "something that prospective employer's value greatly in graduates (Pool \& Sewell, 2007, p.284). Gathering insights from employers is likely to achieve a better link between the syllabus and the profession. In line with this finding, other researchers confirm the importance of taking the market needs into account in translation studies (de Céspedes, 2017; Tosun et al., 2015).

\subsection{Recommendations}

A significant recommendation that can be put forward is to reconsider the amount of learning time within the course distributions of the MA program. Findings from internal and external assessments revealed that the learning time was not adequate. All sources strongly claimed the need for more class hours.

Another important recommendation emphasized by key stakeholders stressed the need for the incorporation of practical experience and opportunities for internship in the MA program. They highlighted the need for more practice in translation in general and in interpreting in particular. Based on their feedback, practice in the translation and interpreting fields can be achieved through providing internship opportunities, conducting concrete field visits and inviting professionals to class. In a similar vein, researchers asserted the importance of including work experience and employability skills in the syllabus of translation studies (de Céspedes, 2017; Pool \& Sewell, 2007). These skills involve the inclusion of simulated professional practices through working on concrete translation projects and inviting professional translators to organise events.

Finally, implementing a tougher admission policy for a better selection of MA students is of paramount importance. Feedback from teachers, the coordinator and employers stressed that some students were weak and were even in the wrong degree though they always sit for preentry test in order to be enrolled in this MA program. 


\section{References}

De Céspedes, B. R. (2017). Addressing employability and enterprise responsibilities in the translation curriculum. The Interpreter and Tanslator Trainer, 11, (2-3), pp. 107-122

Dubin, F. \& Olshtain, E. (1986). Course design: Developing programs and materials for language learning. Cambridge University Press: Cambridge.

Golden, D. W., Braunstein, S., Jimenez, R. B., Mohindra, P., Spektor, A., \& Ye, J. C. (2015). Multi-institutional implementation and evaluation of a curriculum for the medical student clerkship in Radiation Oncology (Article in press). Journal of the American College of Radiology, 13 (2), pp. 203-209.

Gouadec, D. (2000). Notes on translator training (replies to a questionnaire). In International Symposium on Innovation in Translator and Interpreter Training. Intercultural Studies Group

Olvera L. et.al. (2005). Translator training and modern market demands. Perspectives: Studies in Translatlogy. 13 (2)

Pool L. D. \& Sewell, P. (2007). The key to employability: Developing a practical model of graduate employability. Education \& Training, [Online] 49, (4), pp. 277-289. Available: http: //www.emeraldinsight.com/00400912.htm DOI 10.1108/00400910710754435

Ramaswami, S., Sarraf, I., \& Haydon, J. (2012). English language quantitative indicators: Morocco, Algeria and Tunisia. A custom report compiled by Euromonitor International for the British Council. London: Euromonitor International.

Rezvani, R \& Vakilinejad, M. (2014). An Evaluation of Translation Quality Assessment Course: Voices from Instuctors. Procedia-Social and Behavioral Sciences [Online] 98, pp. 1563-1571. Available: http: //www.sciencedirect.com/ DOI: 101016/j.sbspro.2014.03.579

Seddik, A. (2017). Evaluation of the Curricula in the English Language Departments of Higher Education Instituitons in Tunisia. Ph.D. Thesis. Tunisia: Institut Supérieur des Langues de Tunis.

Seddik A. \& A. Selmi (2015, April). Curricula in Translator and Interpreter Training Programs. Paper presented at an international conference on Translation and Interpreting: New Voices on the Marketplace (TINVOM) (ISSHT) Tunis, Tunisia.

Seddik A. \& A. Selmi (2018, May). International Relations' Students' Employability amidst the New Political context in Tunisia: Insights from various stakeholders.Paper presented at an international conference on Impact of Education on Employment: Cases from Germany and Arab countries International Conference organized by Arab-German Young Academy of Sciences and Humanities (AGYA), 1-5 May 2018 (ISSHT) Tunis, Tunisia.

Spiel, C., Schober, B., \& Reimann, R. (2006). Evaluation of curricula in higher education: Challenges for Evaluators. Evaluation Review, 30 (4), pp. 430-450.

Tosun, M., A. Akin \& F. Simsek (2015). Courses on specialized field in undergraduate programs of translation and interpretation departments in Turkey: The importance of couses on specialized field in the specialization process of translator candidates. Procedia- Social and Behavioral Sciences, [Online] 192, pp. 4-10. Available: http: //www.sciencedirect.com/ DOI: $10.1016 /$ j.sbspro.2014.03.579

Wholey, J. S. (2001). Managing for results: Roles for evaluators in a new managemnt era. American Journal of Evaluation, 22 (3), pp. 343-347. 